amount still remained high, being 362 grs., notwithstanding which his condition had greatly improved; but at the end of July the mean quantity was only $202 \cdot 9$ grs., being a reduction of $154 \cdot 1$ grs.

CASE 4.-John C-. The average daily amount of albumen passed after admission on Jan. 12th, 1865 , was 184.05 grs. ; this was considerably decreased by the end of March, when he was discharged from the hospital, $124 \cdot 4$ grs. being then excreted. This quantity, however, was still further reduced when the urine was next examined, on Aug. 5th, 77 grs. being found, showing a diminution of $107 \mathrm{grs}$.

CASE 5. - Martin $\mathrm{H}$ - In this case the patient, at the period of his adunission on Feb. 15th, was excreting 245 grs. of albumen daily; but on July 9th, just before he was sent to the Convalescent Institution, only $6 \cdot 16 \mathrm{grs}$. were found for the day, the patient being in fact almost completely cured.

I must confess that the very striking facts recorded in this paper have greatly surprised me. The impression $I$ had derived from books in reference to Bright's disease was that it was nearly always a fatal and incurable affection, whereas it really is much more amenable to treatment than could have been anticipated-so much so, indeed, as in my belief to fully justify the title $l$ have given to this communication. The particulars recorded appear also to prove that the disease is not exclusively local and organic, but is to a great extent a blood disease.

Wimpole-street, Aag. 1865.

\section{LIGATURE OF THE SUBCLAVIAN ARTERY FOR ANEURISM OF THE AXILLARY.}

By EDGCOMBE VENNING, EsQ., M.R.C.S., ASSISTANT-SURGEON TO THE TIRSY IITE GUARDS, AND LATA HOUSE-SURGEON ro SI. GEORGI'S HOSPLTAL.

Trooper J. C- presented himself at the regimental hospital on the 31st of August, 1864, complaining of considerable pain about the right wrist and shonlder-joint. He stated that eight months previously, in going down some steep stone stairs in barracks, he fell back wards, with his right arm extended, and directed outwards and backwards. The wrist was very painful for some time after, and though a good deal swollen, he continued to do his duty. Only nine days prior to admission did he notice any swelling about the shoulder-joint.

On admission he comylained of considerable pain about the lower third of the right forearm, at which situation on the radial side there was an irregular swelling. This appeared like the remains of an old fructure badly united, and was the result, I believe, of a fracture of the radius caused by the accident, the bone being liept in tolerable position by the vlna, which had not been injured. On examining the shoulder-joint I found a pulsating tumour, about the size of a hen's egg, situated over the course of the axillary artery. The pulsation was very strong, and the bruit in the tumour exceedingly loud, both of which ceased when pressure was made on the subclavian artery. The ulna and radial pulses were much dimininished in force in comparison with the opposite limb. Finding from the patient's accunnt that the tumour had increased rapidly, I requested Mr. Cutler and Mr. Pollock to see the case with me, and they were both of opinion that deligation of the subclavian artery in its third portion should be performed at once. In accorlance with this opinion, having the assistance of both Mr. Cutler and Mr. Pollock, (chloroform having been administered by Mr. Freeman,) I proceeded to perform the operation, and without much difficulty succeeded in tying the artery. The external jugular vein, being in the way, was tied above and below, and cut through, and all small bleeding vessels were ligatured. On the ligature around the subclavian artery being tightened, all pulsation in the tumour ceased. The edges of the wound were brought together with silver sutures and strapping, and the limb was enveloped in cotton wool. When the effects of the chloroform had passed away, I ordered him a liberal diet, and a full dose of opium at bedtime. The following morning I found he had had several hours of refreshing sleep. The pulse was 88 in the minute; the skin was cool, and the tongue clean and moist. The temperature of the affected limb was normal, and the only thing be complained of was a pricking pain throughout the extremity. From this date all went on well; pulsation was felt in the brachial artery on the seventh day after the operation, and on the ninth it was felt quite strong in the radial and ulna at the wrist; but two days after it ceased in the brachial and radial and ulna, and has never been felt since. No bad symptoms. accompanied the cessation of pulsation. No pain was experienced in the aneurismal sac, and on the eleventh day the ligature around the subclavian artery came away. Twentyfour days after the operation the patient left the hospital, the wound having almost entirely healed, and he in good health. The reason for his quitting the hospital so soon was, that smallpox had broken out in the regiment, and I was unwilling to run the risls of his becoming a victim to the malady, as there were several cases in hospital. He left London on a month's furlough for Nuneaton, where on his arrival, as he felt somewhat weak, he placed himself under the care of Mr. Nason. I heard no more of him until the end of October, when I received a letter from Mr. Nason, in which he related to me that he had been sent for to see my patient in consequence of severe hæmorrhage having come on from that portion of the wound made at the operation, which had not healed when he left London. I immediately went to see him, and met Mr. Nason in consultation. Bleeding (although all proper means had been. adopted to arrest it) was still going on. A large abscess had formed beneath the clavicle, accompanied by enormous cedema. of the right upper extremity, and mortification had commenced in the little finger. The question now arose as to where the hæmorrhage came from. We came to the conclusion that it was the result of a large sloughing cavity formed by the abscess. I therefore put my finger into the wound, and broke down all the old adhesions, so as to allow the escape of a considerable quantity of foul pus and blood. No return of bleeding occurred subsequent to this, but unfortunately pyæmia set. in, followed by a series of abscesses, one of which was situated in the elbow-joint, and for a considerable period he hung between life and death, under Mr. Nason's care; but by the untiring care and attention of that gentleman the patient rallied, and so far recovered as to be able to rejoin his regiment, though with an anchylosed elbow-joint, and considerable loss of power in the hand. This latter he is rapidly recovering, and the forearm is at a right angle with the arm; so that thereis every hope of his ultimately having a very useful limb.

The Cavalry Barracks, Windsor, Dec. 1865.

ON A CASE OF

\section{CHOLERA OCCURRING DURING LABOUR.} DEATH IMMEDIATELY AFTER DELIVERY.

By H. E. EASTLAKE, L.K.Q.C.P.,

PHYSICIAN TO THE BRITISH LTING-IN HOSPTTAL, PHYSICIAN-ACCOUCHEUR TO THE ST. MARYLEBOYY DISPEMSARY, ETC.

ON the 30 th ult., I was hurriedly summoned, at about $8 \cdot 30$ : P.M., to see Mrs. U_, aged twenty-one, in her first labour. She resided within a few minutes' walk of my house. I found her in an alarming state of collapse. No pulse was perceptible at the wrists ; the extremities were perfectly cold ; the countenance pinched and anxious, and a bluish hue was perceptible over the body generally. I was told by the attendant that labour commenced about eleven P. M. on the 29 th, and that the most distressing vomiting and purging set in at the same time. The sickness and diarrhoea had therefore continued for more than twenty hours. She had been violently sick shortly before my arrival, and rice-water stools gushed constantly from the bowels. Brandy and beef-tea had both been administered by the rnouth, but were almost instantly thrown up. On examination per vaginam, I found the face presenting, and the os uteri fully dilated. The liquor amnii had only escaped about four hours before my arrival. The fotal head was fairly in the cavity of the pelvis, and the left ear was easily within reach. Without further delay I applied the forceps, and delivered the patient without much difficulty of a very large male infant. The child showed no signs of life whatever. The funis was divided, and the placenta passed away within a few minutes of the birth. The uterus contracted very well, and there was not the slightest hremorrhage. More brandy-andwater was given, but immediately ejected. An offensive watery evacuation now continually trickled from the bowel. The patient's face became ghastly in appearance, and her whole body cold. She was conscious to the last. Her breathing 
became hurried; a dark fluid gurgled from ber mouth, and she ceased to exist within ten minutes of her clelivery.

As far as I can learn she had enjoyed good health during her pregmancy, and had felt well up to the time of setting in of labour.

Welbeck-street, December, 1865.

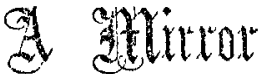

OF THE PRACTICE OF

\section{MEDICINE AND SURGRRY \\ IN THE}

\section{HOSPITALS OE LONDON.}

Nulla auten cualia pro certo nosicendi via, nisi quamplurimas et morborum a isturias, tum aliorum, tum wroprias collectas haber, et inter se compararc. Horgigivi De Sed. et Caus. MTorb., lib. iv. Proumium.

\section{UNIVERSTTY OOLLEGE HOSPITAL.}

CASES OF STORE IN THE BLADDER REMOVED BY LITHOTRITY AND LITHOTOMY.

(Under the care of Mr. Henry Thompsoy.)

THERE is much difierence of opinion as to the best means to be employed in cutting for stone. Many surgeons remain perfectly content with the lateral operation, advocated especially by Cheselden, and slightly modified by succeeding opeators. But there are also some-and the number has, perhaps, increased of late years - who consider that, in certain cases, recourse may be had with advantage to other procedures. Of these, the median operation, introduced by Mr. Allarton some ten years ago, has been the most extensively practised. The advartage, doubtless, consists in the fact that by this process the pelvic fascic are not opened, and thus a considerable source of danger is avoided. Its disadvantage, on the other hand, lies in the very small space which is provided for the extraction of the stone; so that, if this chance to be large, laceration, not only of the prostate, but of the neck of the bladder, is difficult, if not impossible, to be avoided. Dupuytren's operation con sists in a crescentic cut between the anus and scrotum, fol lowed by the introduction into the groove of the staif of a double-bladed lithotome, which, being withdrawn, makes a cut on each side into the neck of the bladder and each lateral lobe of the prostate. The operation performed by Mr. Thompson in the case presently to be narrated, combines some of the features of these two last methods. It was introduced by Civiale in 1829, and is described in Mr. Thompson's work "Practical Lithotomy and Lithotrity," p. 57.

We are indebted to Mr. Harly Simith for the notes of the cases.

LARGE STONE IN THE BIADDER OF A MAN AGED TWENTYFIGHT YEARS, SUCCESSFULCY REMOVED BY LITHOTRITY.

E. B-_ aged twenty-eight, a puddler, admitted April 27th, 1865. About five or six years ago he had stricture, up to which time he had been in good health. Six months ago he was admitted into a large provincial hospital with stone. He remained there a month, and then let because he would not submit to lithotomy, since which he has not been under medical treatment.

On admission, the patient complained of scalding during micturition whenever he makes any exertion; he has no burning pain when he is quiet. Says he has not much difficulty in passing arine. The urine is pale in colour, turbid, depositing a sediment, specific gravity 1023 , slightly acid, no albumen, and contains phosphates.

April 28th. - Mr. Thompson sounded him, and detectel a stone measuring an inch and a balf in diameter. Mr. Thompson recommended lithotomy, but did not refuse to perform lithotrity if the patient preferred it.

May 3rd. - Mr. l'lompson crushed with the fenestrated lithotrite a large phosphatic stone.
Bth. The patient has had no fever. He has remained on his back since the operation. Ordered to pass urine for the first twenty-four hours after the operation in the recumbent posture. Complains of pain in the back of the head, and slight pain in passing urino.

9th.-Another sitting with fenestrated lithotrite; much débris followed.

12th. - Anvther sitting with the flat-bladed lithotrite.

17th.-Another sitting with the same lithotrite. Urine much clearer; much débris removed. Holds his urine for two and three hours. No pain; no fever.

19th. - Another sitting (the fifth) with fenestrated lithotrite; ew fragments removed.

21st. - The house-surgeon passed a catheter, and drew off some of his water. A small fragment has lodged in the prissage, which causes slight pain in micturition. The patient passed blood for two hours afterwards.

22nd. - This moming he still complains of pain during micturition. There is no hæmaturia.

23rd.--Passes no blood; still complains of a fragment in the passage. Skin hot; no thirst. Sixth sitting: Mr. 'Thompson passed a No. 12 bougie; then a lithotrite. With the latter some fragments were removed.

24th.-Has slight pain in micturition. Seventh sitting : Mr. Thompson introduced the lithotrite, and crushed a small fragment.

26th. - Eighth sitting: Mr. Thompson passed the sound; then the lithotrite. No fragments whatever to be detected.

30th.-Ninth sitting: Mr. Thompson introduced the sound, but could not detect any fragments.

31st. - The patient discharged, perfectly well and hearty, and iree from all symptoms of stone.

STONE IN THE BLADDER OF A MAN AGED STXTY-TWO YEARS, REMOVED BY LITHOTRITY ; RELIET; DEATH FOUR MONTHS AFTER FROM CANCER.

G. B-_- aged sixty-two, labourer, admitted April 18th, 1865. Last Christmas he first noticed gravel. Twelve months previous to this he suffered with pain in the back. On one occasion since the occurrence of gravel a calculus lodged in his urethra; this was pushed back by his medical attendant. From this time until his admission his symptoms have remained unrelieved. He passes urine very frequently, which is accompanied with pain; sometimes has a difficulty in voiding it, at other times none.

April 20 th. - Mr. Thompson introduced a flat-bladed lithotrite, and crushed a small stone. Ordered twenty grains of bicarbonate of potash and half a drachm of the tincture of Hyoscyamus in an ounce of water three times a day, and a pint ": the decoction of triticum repens daily. The patient had light rigors.

2.2nd. - Patient much better; urine improved in colour.

24th. - Urine further improved; no sediment, but a quantity of stringy mucus, which entangles fragments of calculi.

25th. Complains of pain in passing urine, and slight pain in the lower part of the back. Urine improved in colour; shreds of mucus in it.

26th.-Urine better; mucus less.

At the end of April and beginning of May the lithotrite was introduced two or three times, and only small fragments found.

May 8th.-Passed several small pieces of calculous matter since last sitting, and now feels a cutting pain during micturition. Bowels confined. Has his bladder syringed out with weak solution of acetate of lead every morning.

17th.-Holds urine three hours; rises in the night three times; little pain at the end of micturition. Urine better, but not quite clear. Passed the last fragment a week or ten days ago.

19th.-Mr. Thompson passed the lithotrite, and after a careful examination could not detect any calculous matter in the bladder.

20th.-Discharged, free from symptoms of his malady.

Thus far the patient had been greatly relieved. But he was not long before he had other symptoms, clearly not referable to calculous disease. He cied at the end of September, and the post-mortem examination disclosed extensive renal disease and well-marked cancer of the blarker. No stone was found in that viscus, but there was, and had been for some time previous to death, a large quantity of muco-purulent matter with abundance of phosphatic deposit in it.

LARGE STONE IN THE BLADDER OF A MAN AGED SEVENTYONE YEARS SUCUESSFULLY RTMOVPD BY LTTHO'TOMY.

5. P_, aged seventy-one, was admitted on the 4th of 